\title{
A Cross-Sectional Study: Progression into Renal Replacement Therapy in Post Coronary Bypass Artery Graft Surgery Patients with Varying Pre- Operative Serum Creatinine Levels
}

\author{
M. Azizan Petra ${ }^{1 *}$, M. Ezani Taib ${ }^{1}$, I. F. Gaafar ${ }^{1}$
}

${ }^{1}$ Institut Jantung Negara, Kuala Lumpur, Malaysia

DOI: $10.36347 /$ sjams.2021.v09i03.025

| Received: 12.02.2021 | Accepted: 10.03.2021 | Published: 17.03.2021

*Corresponding author: M. Azizan Petra

Abstract

Original Research Article

Objective: To evaluate the likelihood of progression to renal replacement therapy (RRT) in patients with isolated coronary artery bypass graft (CABG) surgery with different serum levels of creatinine. Methods: This is a cross sectional study whereby patients included is those who had isolated CABG from $1^{\text {st }}$ January 2015 to $31^{\text {st }}$ December 2016. The patients are allocated into 3 different groups according to their serum creatinine level; $<120 \mu \mathrm{mol} / \mathrm{L}, 120-$ $200 \mu \mathrm{mol} / \mathrm{L},>200 \mu \mathrm{mol} / \mathrm{L}$. Baseline characteristics were also measured. Patients who have end stage renal disease (ESRD) or requiring dialysis pre-operation were excluded in the study. The primary outcome measured is the use of renal replacement therapy (RRT) post CABG. Sub analysis of the RRT group is also done to look at the proportions of Continuous Veno-venous Hemofiltration (CVVH) and Hemodialysis (HD) chosen. Secondary outcomes measured include mortality post CABG, length of intensive care unit (ICU) stay and total length of hospital stay. Results: Total of 2313 patients was included in the study. Baseline characteristic were measured. The mean age was 59.7 years old with majority of the patients are male $(83.7 \%)$. Amongst the 3 groups of serum creatinine level, hypertension and diabetes have the highest proportion in the $>200 \mu \mathrm{mol} / \mathrm{L}$ creatinine group $(94.8 \%$ and $84.4 \%)$ respectively. The rest of the measured baseline characteristic including cholesterol, chronic obstructive pulmonary disease, cross-clamp time and cardiopulmonary bypass time (CPB) were similar. The proportion of patients receiving RRT were highest (48.1\% $\mathrm{P}<0.001)$ in the $>200 \mu \mathrm{mol} / \mathrm{L}$ creatinine group. In the $120-200 \mu \mathrm{mol} / \mathrm{L}$ creatinine group $(10.4 \% \mathrm{P}<0.001)$ received RRT while in the $<120 \mu \mathrm{mol} / \mathrm{L}$ creatinine group, $(1.7 \% \mathrm{P}<0.001)$ of the patients received RRT. For the total RRT patients, CVVH modality (3.7\%) was used more than HD modality $(1.8 \%)$. Mortality was highest $(11.4 \% \mathrm{P}<0.001)$ in the $>200 \mu \mathrm{mol} / \mathrm{L}$ creatinine group. Mortality in the $120-200 \mu \mathrm{mol} / \mathrm{L}$ creatinine group and $<120 \mu \mathrm{mol} / \mathrm{L} \mathrm{creatinine}$ group were $(6.4 \%$ and $2.1 \%, \mathrm{P}<0.001)$ respectively. Length of ICU stay and total of length of hospital stay were similar. Conclusion: This study shows that patients who have renal impairment preoperatively are more likely to require RRT post CABG and it appears that the more deranged the creatinine level, the greater the likelihood will be. This indicates that aggressive measures at optimizing patients preoperatively is paramount.

Keywords: Progression, Renal Replacement Therapy, Coronary Bypass, Surgery Patients, Pre-Operative Serum Creatinine.

Copyright (C) 2021 The Author(s): This is an open-access article distributed under the terms of the Creative Commons Attribution 4.0 International License (CC BY-NC 4.0) which permits unrestricted use, distribution, and reproduction in any medium for non-commercial use provided the original author and source are credited.

\section{INTRODUCTION}

It is well known that renal replacement therapy has been the practice for the treatment for acute kidney injury [1]. Acute kidney injury (AKI) is a common and potentially serious postoperative complication after cardiac surgery [2]. AKI is defined as an abrupt and sustained decrease in renal function from a baseline resulting in retention of nitrogenous (urea and creatinine) and non-nitrogenous products [3]. This in effect will cause metabolic disturbances such as hyperkalemia and metabolic acidosis [3].
AKI occurs in $5 \%$ to $45 \%$ after cardiac surgery depending on the diagnostic AKI criteria and type of cardiac surgery [2]. Out of the patients who developed AKI post cardiac surgery, there is a higher rate of mortality $[2,4]$ and it is one of the causes of significant morbidities [4]. Some studies quoted that up to $2 \%$ of AKI patient will require RRT [3]. Other studies quoted between less than $1 \%$ to $6 \%$ will need RRT [5]. The establishment of RRT has been proposed as a mean of reducing the in-hospital mortality in post-operative patients developing AKI [3]. 
Various factors have been established as the cause of AKI resulting in need for RRT in postoperative patients, including pre-existing renal dysfunction [3]. This study aims to evaluate the prognostic significance of pre-operative levels of creatinine and the subsequent need for post-operative RRT in isolated CABG patients.

\section{MeTHODS}

Patients who are included are isolated CABG patients between $1^{\text {st }}$ January 2015 to $31^{\text {st }}$ December 2016 in Institut Jantung Negara, Kuala Lumpur, Malaysia. Patient information was extracted from the electronic database. The patients are allocated into 3 different groups according to their serum creatinine levels; <120 $\mu \mathrm{mol} / \mathrm{L}, 120-200 \mu \mathrm{mol} / \mathrm{L},>200 \mu \mathrm{mol} / \mathrm{L}$. Patients with ESRD or who had dialysis before surgery were excluded in the study. Baseline characteristics were measured in all groups; age, gender, hypertension, hypercholesterolemia, COPD, CPB time and cross clamp time. The primary outcome measured were the use of RRT in the 3 groups post-operatively. The proportions were then sub-analyzed to the types of RRT used; i.e. CCVH or HD. Secondary outcomes measured were mortality, length of ICU stay and total length of hospital stay. Data analysis was carried out with IBM SPSS Statistics 24.

\section{RESUlTS}

A total of 2932 isolated CABGs were done between $1^{\text {st }}$ January 2015 to $31^{\text {st }}$ December 2016. After applying the exclusion criteria, a total of 2313 were included in the study. After allocation to 3 different groups (fig. 1); there were 1841 patients in the $<120 \mu \mathrm{mol} / \mathrm{L}$ creatinine group. There were 393 and 79 patients in the $120-200 \mu \mathrm{mol} / \mathrm{L}$ and $>200 \mu \mathrm{mol} / \mathrm{L}$ creatinine group respectively. Table 1 shows the baseline clinical characteristics in all of the three different serum level creatinine groups. The age of the patients in all 3 groups were similar where the mean age is $59.7 \pm 8.5$ years old. Majority of the patients were male $(83.7 \%)$ with the highest proportion of this gender observed to be in the $120-200 \mu \mathrm{mol} / \mathrm{L}$ creatinine group. A total of $83.6 \%$ of all the patients has hypertension with the highest proportion $(94.8 \%)$ being in the $>200 \mu \mathrm{mol} / \mathrm{L}$ creatinine group. $57.5 \%$ of the total patients have diabetes of which the highest $(84.8 \%)$ was noted to be in the $>200 \mu \mathrm{mol} / \mathrm{L}$ creatinine group. $76 \%$ of all of the patients has hypercholesterolemia. Proportion of patients having COPD were also similar in all groups where the mean is $4.2 \%$. Cross clamp time and CPB times again were similar in all three groups where the mean is $72 \pm 31$ minutes and $92 \pm 36$ minutes respectively.

Table 2 shows the results of the primary outcome. The proportion of patients receiving RRT were highest $(48 \% \quad \mathrm{P}<0.001)$ in the $>200 \mu \mathrm{mol} / \mathrm{L}$ creatinine group. In the $120-200 \mu \mathrm{mol} / \mathrm{L}$ creatinine group $(10.4 \% \quad \mathrm{P}<0.001)$ received $\mathrm{RRT}$ while in the
$<120 \mu \mathrm{mol} / \mathrm{L}$ creatinine group $(1.7 \% \mathrm{P}<0.001)$ of the patients received RRT. Fig. 2 shows the result of the sub-analysis of the modalities of RRT used. In all of the RRT patients, CVVH were commonly used (3.7\%) when compared to HD (1.8\%). However, in the >200 $\mu \mathrm{mol} / \mathrm{L}$ creatinine group alone, HD is more common $(31.6 \%)$ than CVVH $(26.6 \%)$.

Table 3 shows the secondary outcome where mortality where is highest $(11.4 \% \mathrm{P}<0.001))$ in the $>200 \mu \mathrm{mol} / \mathrm{L}$ creatinine group. Mortality in the 120-200 $\mu \mathrm{mol} / \mathrm{L}$ creatinine group and $<120 \mu \mathrm{mol} / \mathrm{L}$ creatinine group were $(6.4 \%$ and $2.1 \%, \mathrm{P}<0.001)$ respectively. The length of ICU stay and total length of hospital stay is similar to all 3 groups where the mean is $2 \pm 1$ days and $9 \pm 8$ days respectively.

\section{DisCUSSION}

RRT remains one of the treatments of AKI. This study is looking at the use of RRT in different groups of serum level creatinine post isolated CABG. For the baseline characteristics, some data are comparable to published international studies. We found that in this study, the majority of the patients were male $(83.7 \%)$ which was also reflected in another study [6] which also showed a majority of the male cardiac patients respectively. Not surprisingly, hypertension and diabetes has the highest proportion in the most severe renal impairment group which again is similar observed in one other study [8].

In general, $1 \%$ to $6 \%$ of post cardiac surgical patients require dialysis $[3,5]$. This study shows consistent results with other studies where this study showed the use of RRT is $4.8 \%$. It has been established that the causes of renal hypo-perfusion and subsequent AKI needing dialysis is variable [3] and one of the factors is pre-existing renal impairment in preoperative cardiac surgery [7]. This study shows that the use of RRT is highest in those with the most impaired creatinine levels. This study also shows that even mild increase of renal impairment will increase the likelihood of RRT post-operatively. This finding is once again consistent with the observation of another study (8). It has also been reported that the presence of mild renal failure was an independent significant predictor of the development of AKI [8].

However, in the $<120 \mu \mathrm{mol} / \mathrm{L}$ creatinine group, $1.7 \%$ of the subject required RRT. In this group, EGFR was measured where it is statistically similar in both subjects that require RRT and who do not require RRT (Table 4).

Browner and Mangano suggested that impaired renal function is an important predictor for mortality [8]. In this study, the mortality rate is highest $(11.4 \%$, $\mathrm{P}<0.001)$ ) in the most impaired renal function group compared to $(2.1 \% \mathrm{P}<0.001)$ in the least impaired renal function group. An international study showed that a 
M. Azizan Petra et al; Sch J App Med Sci, Mar, 2021; 9(3): 424-427

pre-operative serum creatinine of more than $2.0 \mathrm{mg} / \mathrm{dl}$ (176.8 umol/L equivalent) was significantly associated with increased rates of post-operative deaths, with an odds ratio of 2.01 [8]. We have found that for the total all cause-mortality rate in post $\mathrm{CABG}$ is $3.1 \%$ for isolated $\mathrm{CABG}$ which is again comparable to international data (2-3\%)[9].

Several studies show that there is an increased in hospital stay in patients who developed AKI [8, 9]. Interestingly, our analysis shows that that there is no significant difference in terms of the length of hospital stay regardless of the level of the serum creatinine. The ICU length of stay is also similar in all groups. This could be that RRT is instituted early and that there is liberal use of RRT our Centre.

However, this study still has several of its own limitations. One of the limitations is that this study was conducted from a single centre. However, to our current knowledge, there has been no similar study that has being conducted before in this region. The other limitation is that this is a cross sectional study which only reflects the group of patient at one specific point in time. Thus, may not accurately represent the general population at a different time frame for example. This study also didn't independently analyze the effect of mortality, length of hospital and ICU stay on patients after receiving RRT.

In conclusion, this study showed that patients who have renal impairment pre-operatively are more likely to require RRT support post $\mathrm{CABG}$, with those with the more severe renal impairment at baseline to be more at risk. Pre-existing renal impairment prior to surgery also has negative effect on mortality. However, in our centre, length of hospital stay and length of ICU stay is not affected.

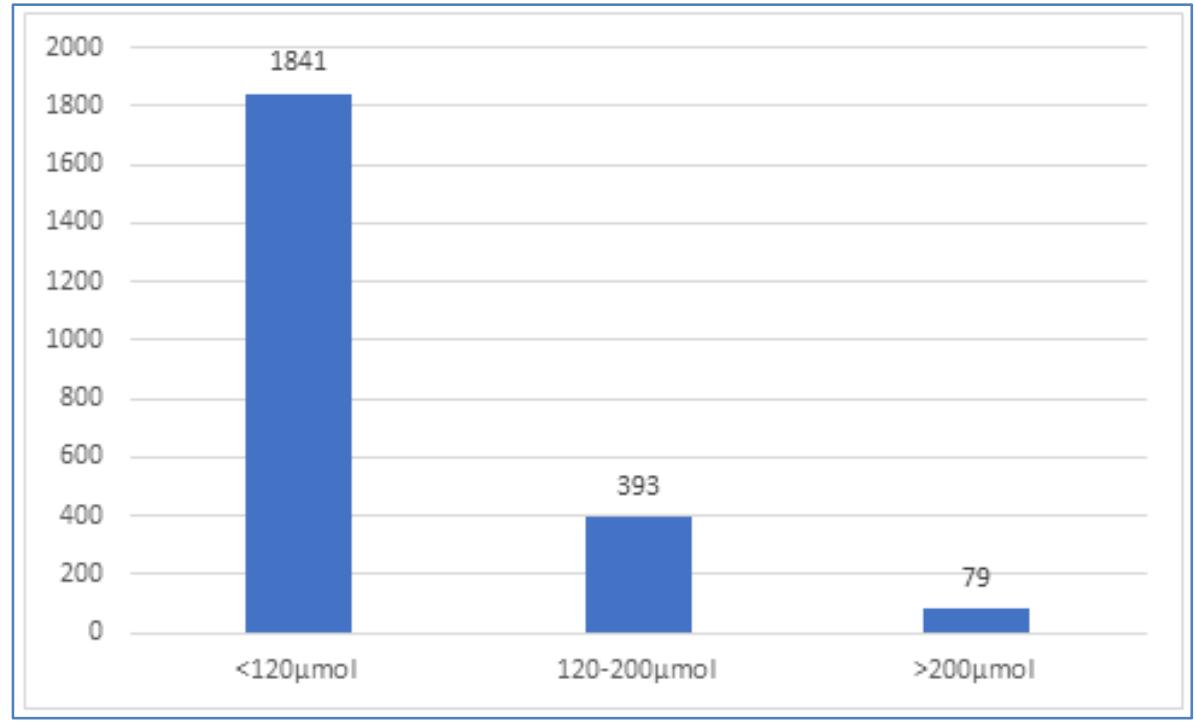

Fig-1

Table-1

\begin{tabular}{|l|c|c|c|c|}
\hline & $\mathbf{< 1 2 0} \boldsymbol{\mu m o l}$ & $\mathbf{1 2 0 - 2 0 0} \boldsymbol{\mu m o l}$ & $\mathbf{> 2 0 0 \mu m o l}$ & TOTAL \\
\hline Male, n (\%) & $1516(82.3)$ & $354(90.1)$ & $67(84.8)$ & $1937(83.7)$ \\
\hline Female, n (\%) & $325(17.7)$ & $39(9.9)$ & $12(15.2)$ & $376(16.3)$ \\
\hline Age, years & $59.2 \pm 8.5$ & $61.5 \pm 8.3$ & $61.0 \pm 7.9$ & $59.7 \pm 8.5$ \\
\hline Hypertension, n (\%) & $1475(81.4)$ & $355(91.3)$ & $73(94.8)$ & $1903(83.6)$ \\
\hline Hypercholestrol, n (\%) & $1371(75.3)$ & $306(78.7)$ & $62(78.5)$ & $1739(76.0)$ \\
\hline Diabetes, n (\%) & $1007(55.1)$ & $247(63.2)$ & $65(84.4)$ & $1319(57.5)$ \\
\hline Chronic pulmonary disease, n (\%) & $79(4.3)$ & $16(4.1)$ & $3(3.8)$ & $98(4.2)$ \\
\hline Cross Clamp Time (Minutes) & $72 \pm 31$ & $73 \pm 31$ & $63 \pm 25$ & $72 \pm 31$ \\
\hline CPB Time (Minutes) & $92 \pm 36$ & $93 \pm 36$ & $85 \pm 32$ & $92 \pm 36$ \\
\hline
\end{tabular}

Table-2

\begin{tabular}{|c|c|c|c|c|c|}
\hline & $<120 \mu \mathrm{mol}(\%)$ & $120-200 \mu \mathrm{mol}(\%)$ & $>200 \mu \mathrm{mol}(\%)$ & TOTAL (\%) & $P$ value \\
\hline RRT, n (\%) & $32(1.7)$ & $41(10.4)$ & $38(48.1)$ & $111(4.8)$ & $<0.001$ \\
\hline
\end{tabular}




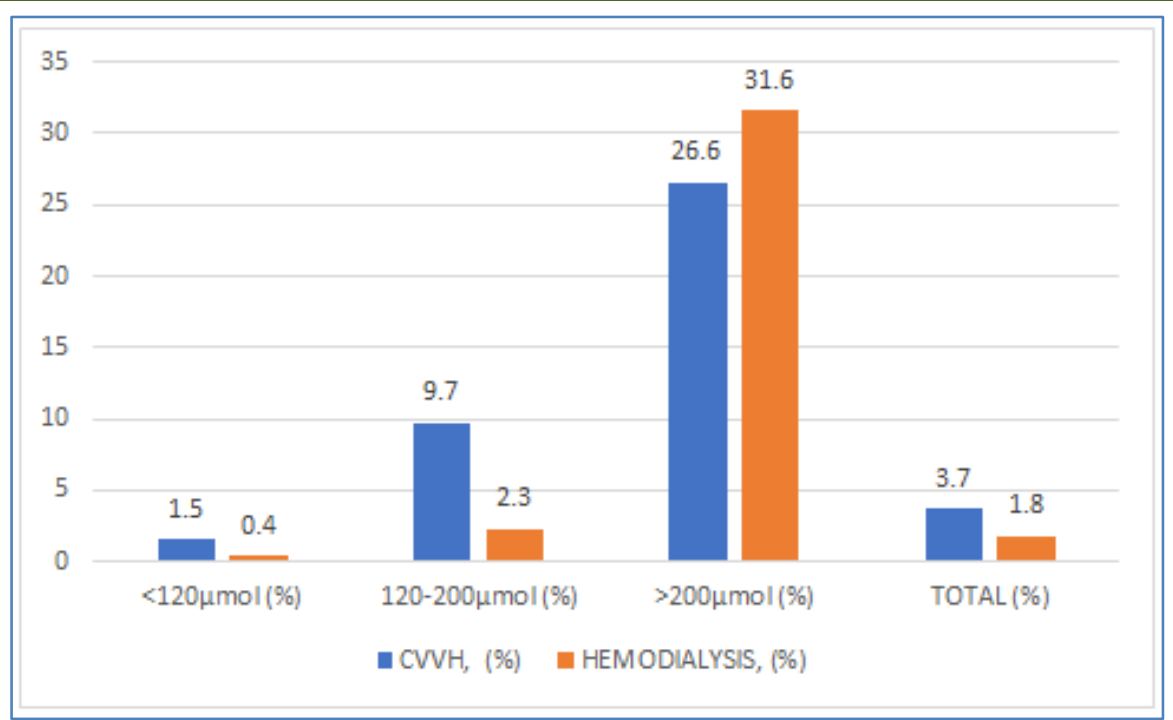

Fig-1

Table-3

\begin{tabular}{|l|c|c|c|c|c|}
\hline & $\mathbf{< 1 2 0} \boldsymbol{\mu m o l}$ & $\mathbf{1 2 0 - 2 0 0} \boldsymbol{\mu m o l}$ & $\mathbf{> 2 0 0} \boldsymbol{\mu m o l}$ & TOTAL & P value \\
\hline Mortality, n (\%) & $38(2.1)$ & $25(6.4)$ & $9(11.4)$ & $72(3.1)$ & $<0.001$ \\
\hline ICU Stay (Day) & $2 \pm 1$ & $2 \pm 1$ & $3 \pm 2$ & $2 \pm 1$ & \\
\hline Length of admission (Day) & $9 \pm 7$ & $11 \pm 10$ & $12 \pm 8$ & $9 \pm 8$ & \\
\hline
\end{tabular}

Table-4

\begin{tabular}{|l|c|c|}
\hline & NO RRT & RRT \\
\hline EGFR & & \\
\hline MEAN \pm SD & $79.3 \pm 25.3$ & $71.3 \pm 27.0$ \\
\hline MEDIAN (MIN, MAX) & $75.2(24.5,227.7)$ & $65.4(41.4,174.6)$ \\
\hline
\end{tabular}

\section{REFERENCE}

1. Marenzi G, Cosentino N, Marinetti A, Leone AM, Milazzo V, Rubino M. Renal replacement therapy in patients with acute myocardial infarction: Rate of use, clinical predictors and relationship with inhospital mortality. Int $\mathbf{J}$ Cardiol [Internet]. 2017;230:255-61. Available from: http://dx.doi.org/10.1016/j.ijcard.2016.12.130

2. Skarupskienė I, Adukauskienė D, Kuzminskienė J, Rimkutė L, Balčiuvienė V, Žiginskienè E. Mortality prediction in patients with acute kidney injury requiring renal replacement therapy after cardiac surgery. Medicina (B Aires). 2017;1-7.

3. Elahi M, Asopa S, Pflueger A, Hakim N, Matata B. Acute kidney injury following cardiac surgery: impact of early versus late haemofiltration on morbidity and mortality. Eur J Cardio-thoracic Surg. 2009;35(5):854-63.

4. Shin SR, Kim WH, Kim DJ, Shin I-W, Sohn J-T. Prediction and Prevention of Acute Kidney Injury after Cardiac Surgery. Biomed Res Int [Internet]. 2016;2016(Table 1):1-10. Available from: https://www.hindawi.com/journals/bmri/2016/2985 148/

5. Mariscalco G, Lorusso R, Dominici C, Renzulli A, Sala A. Acute kidney injury: A relevant complication after cardiac surgery. Ann Thorac Surg [Internet]. 2011;92(4):1539-47. Available from:

http://dx.doi.org/10.1016/j.athoracsur.2011.04.123

6. Mehta RH, Grab JD, O’Brien SM, Bridges CR, Gammie JS, Haan CK. Bedside tool for predicting the risk of postoperative dialysis in patients undergoing cardiac surgery. Circulation. 2006;114(21):2208-16.

7. Kilo J, Margreiter JE, Ruttmann E, Laufer G, Bonatti JO. Slightly elevated serum creatinine predicts renal failure requiring hemofiltration after cardiac surgery. Heart Surg Forum. 2005;8(1):348.

8. Anderson RJ, O'brien M, MaWhinney S, VillaNueva CB, Moritz TE, Sethi GK. Renal failure predisposes patients to adverse outcome after coronary artery bypass surgery. VA Cooperative Study \#5. Kidney Int [Internet]. 1999;55(3):1057-62. Available from: http://www.nature.com/ki/journal/v55/n3/abs/4490 668a.html\%5Cnhttp://www.ncbi.nlm.nih.gov/pubm ed/10027944

9. Hawkes AL, Nowak M, Bidstrup B, Speare R. Outcomes of coronary artery bypass graft surgery. Vasc Health Risk Manag. 2006;2(4):477-84. 